\title{
The Underlying Public Attitude toward the Ideal Role of Government in Socio- Economic Intervention in Thirty-Years of Evidence from the ISSP
}

Nate Breznau, University of Bremen, breznau.nate@gmail.com

\begin{abstract}
Since the inception of the ISSP's Role of Government module, many scholars assumed the 'ideal role' battery measured the effects of a single unobserved attitude held across individuals and societies. Attempts to substantiate this assumption offer sparse confirmatory evidence. Therefore, this research brings the most data and comprehensive measurement models thus far to investigate a single underlying attitude. The data from 1986-2017 in 43 countries suggests a latent ideal role attitude; however, measurement varies somewhat by historical institutions and levels of development across societies. At first the data seem to fail metric invariance tests as a first step in establishing the latent attitude. When applying corrections for a potential second attitude toward social insurance, and allowing for diverse effects of GDP, socialism or Communist authoritarian institutional legacies, metric invariance comes into focus and explains the data to a degree that most critics find acceptable.
\end{abstract}




\section{THE ROLE OF GOVERNMENT}

The International Social Survey Program's (ISSP) "Role of Government” (RoG) module is the longest running, widest coverage and publicly available comparative survey of public preferences for government intervention into socio-economic affairs in the world. The surveys from this module are the empirical backbone of comparative social welfare state research. Those concerned with public opinion, mass policy preferences and individual attitudes regularly employ the RoG questions about what the government should or should not be responsible for regarding society, labor markets and the economy. I focus on the "ideal role" battery of questions in the RoG - asking about government socio-economic intervention in a variety of means to promote social welfare.

The topic of government socio-economic intervention dates back to the inception of nation states where politicians and parties hotly debated what degree a national government should pool risks, intervene in the labor market, and provide social security; and how these things were or were not necessary components of democratic governance or socialist versus laissez faire systems (Briggs 1961; Huber and Stephens 2001). Given the timing of the survey design in the early 1980s, it is likely that the Cold War and the swift rise of liberalism among certain countries kept this topic highly salient among the public, policymakers, rhetoricians and those designing the ISSP questionnaire (Friedrich 1955; Gamble 1994; Hayek 1996). Certainly, comparative social policy and welfare state research pays close attention to how national state systems differ (Ebbinghaus 2012). Many of these scholars hypothesize that public preferences are shaped by or themselves shape these inter-societal differences (Bowles 1998; Jæger 2006; Meier Jaeger 2009; Wendt, Mischke, and Pfeifer 2011). Scholars from sociology, political science, economics and several domain-specific interdisciplinary areas such as public opinion or social policy research measure attitudes or public opinion from the ideal role battery with the goal of linking to the longstanding public and academic debate over the ideal level of intervention in socio-economic affairs.

The ideal role battery starts with the common question heading, "On the whole, do you think it should or should not be the government's responsibility to..." (in verbatim English), followed by the following seven items: "provide a job for everyone who wants one", "keep prices under control", "provide health care for the sick", "provide a decent standard of living for the old", "provide industry with the help it needs to grow", "provide a decent standard of living for the unemployed", "reduce income differences between the rich and poor" ${ }^{\prime}$. These questions have face validity in measuring a potential underlying attitude because each question asks in an identical way about the governments ideal role and then offers a range of social and economic areas for intervention that arguably all contribute to the promotion and insurance of welfare in society. However, the architects of the ISSP did not have a latent variable in mind during construction of the ideal role battery and were interested more in "item-by-item frequency distributions"2. Also, the evidence does not provide strong support of the face validity of the ideal role battery.

A look at some of the most highly cited literature across-disciplines demonstrates both widespread use of the ideal role questions and lack of consensus in what the questions measure. For example, Roller (1994:

\footnotetext{
${ }^{1}$ Question 30, A-G, British Questionnaire, “ZA1490_bq.pdf”, available at www.gesis.org

${ }^{2}$ Email exchange with M.D.R. Evans, 9/28/2018.
} 
Table 2) uses the mean of individual responses to all seven ideal role questions to demonstrate 'ideological' differences between Eastern and Western Germany; he labels these "expectations regarding the role of government" although he does not engage in tests of measurement validity. Svallfors (2010) follows a similar method but includes Cronbach's alpha calculations to support use of the mean of the seven items. Both of these analyses offer no modeling of error or testing of the metric properties of the items across samples, which would be a necessary step according to best practices in measurement modeling of survey data (Bollen 1989). Others, found that there are two different underlying attitudes among these seven items, one toward social protection such as direct economic intervention to provide labor market chances or minimum assistance and one toward social insurance via social security policies that individuals earn or fund such as contributions to pensions and health care (Blekesaune and Quadagno 2003; Döring 1994). Jonathan Kelley, among the founders of the ISSP, ran initial LISREL exploratory factor analyses on the first round of ISSP data and found two distinct factors among the ideal role battery ${ }^{3}$.

Other scholars analyze single-items independently (Guillaud 2013; Kikuzawa, Olafsdottir, and Pescosolido 2008; Meier Jaeger 2009). Scholars such as Brady and Finnigan (2014:38) dichotomize these single-items to account for a theory that different answer categories are, "unlikely" to have "consistent meanings cross-culturally" although they find strong Cronbach's alpha scores for an underlying six-item scale in the ideal role battery; all items except price controls. They therefore analyze this as a valid underlying latent variable in a sensitivity analysis. Other studies found similar correlational evidence of these six-items forming a single scale (Breznau 2017; Brooks and Manza 2006).

Without reviewing the entire literatures across disciplines and thematic areas, it is clear that scholars often have a theory of some kind of general attitude toward government intervention or role as a social welfare state. Ariely and Davidov (2012) employ much stronger measurement methods via multi-group confirmatory factor analysis of all seven items plus an eighth regarding the government providing financial assistance for university students. They do not support full scalar invariance, but they show that after allowing for certain logical forms of country-specific heterogeneity leads to a statistically supported latent variable for comparison across Britain, Germany, Sweden and the United States. Although this is evidence in the direction of a single underlying latent variable, it only applies to four countries. I am aware of no study that systematically takes on a theory of a single ideal role of government attitude for all countries in the ISSP. Therefore, I attempt to fill this gap using the gold standard for comparative measurement equivalence: structural equation modeling (SEM) techniques to asses measurement invariance (Davidov et al. 2012; Hayduk 2016). The working hypothesis for testing equivalence is the existence of equivalence. The first requirement for this is metric equivalence, a state where all items have the same relative meaning across societies and time when taken in comparison to the underlying latent variable

Given that no one tested these hypotheses across the ISSP previously suggests that either researchers did not see the face validity of all seven questions in the ideal role battery, or perhaps tested it but could not substantiate it. Given a publication bias against 'non-findings' such as no support of a single latent ideal role

\footnotetext{
${ }^{3}$ Unpublished results shared in an email exchange with Jonathan Kelley, 9/28/2018.
} 
attitude it is possible that researchers hedged or cherry-picked the questions or the specific samples that provided the best results. Something akin to p-hacking (Wicherts et al. 2016). Or they might have found the items or samples that produced results and then invented theory unique to those items to explain it. Something known as HARKing (Munafò et al. 2017). This is not to indict previous research but to raise a healthy skepticism over the choice of the lack of invariance testing in the literature. It proposes that we cannot be certain what we as comparative social researchers are measuring in terms of ideal role attitudes if we do not have proof.

\section{A COMmon Underlying IdeAl Role of Government AtTitude?}

Each of these seven questions asks about the "government's responsibility" to create labor market opportunities of jobs and support of industry, distribute incomes horizontally across similar cohorts and vertically within individuals' life courses from prime working age to retirement, improve public health, and keep prices in-check to benefit consumers. In short, the questions ask normatively whether the government should be more or less of a welfare state. This denotative consistency suggests face validity. Scholars routinely measure singular attitudinal responses to survey questions as social policy preferences (emphasis on the plural), but they tend to source these preferences as caused by something institutional about the welfare state (emphasis on singular) (Bean and Papadakis 1998; Gingrich 2014). So long as there is some degree of saliency to the topic, the singular 'welfare state' provides an attitude-object toward which each individual is will have some positive or negative position; a position that of course varies in direction and strength, and changes in response to contextual conditions (Eagly and Chaiken 1993).

This does not suggest that individuals do not attitudinal positions toward each domain of policy, but that they also have a higher-order, more general, position about govenrment socio-economic intervention. There are an innumerable range of theoretically possible government interventions in socio-economic affairs. Here I focus on social welfare, something the government does perpetually in society ${ }^{4}$. Welfare state researchers, such as those reviewed in the previous section, speak of the welfare state as a singular concept or entity, but the open question here is whether public attitudes reflect this conceptualization. Moreover, face validity puts all of the 'objective' burden into the subjective perception of the researcher. Alone, face validity is not enough to substantiate measurement instruments, it needs the support of statistical tests.

Over 100 years ago the theory and statistical methods for identifying latent traits of individuals or populations, such as intelligence or policy preferences, entered the quantitative social science mainstream (Thurstone 1928). The methods developed by Spearman, Thurstone, Galton and others are known today as factor analysis. Factor analysis is a major component of structural equation modeling, and refers to a broad spectrum of methods. In the factor analytic tradition, researchers seek to identify factors - these are latent variables measuring unobserved characteristics or traits common in a population. They can be triangulated by observing their causal impact on other phenomena such as answers to test questions or survey responses, as is the case at hand. But this requires very strong assumptions.

\footnotetext{
${ }^{4}$ Other research considers "intervention" as something the government does only during particular times of depression or crisis (Hasenfeld and Rafferty 1989)
} 
According to theory, a factor is a fundamental kind of variable. It is supposed to characterize everyone in the population. It is supposed to display similar measurement properties across populations. When this is not true, the information in the factor differs for subpopulations, which is prima facie evidence that the factor is biased (Cudeck 2007:6).

To claim evidence or discovery of a "factor" for an entire population or sub-population is a major argument. It should arise out of careful investigation and thorough supporting evidence. The potential of factors taking on different meanings, i.e., measurement properties, across sub-groups is a serious concern of population-based research (Millsap and Meredith 2007).

In order for latent factors to be comparable across societies factorial invariance is a necessary condition. At a basic level this means that the measurement variables show strong inter-item correlations, strong factor loadings (i.e., standardized regression coefficients predicting the latent factor), and pass the scrutiny of goodness-of-fit tests for the whole population and when constraining factors to be identical within sub-groups. This latter test involves a researcher fixing the factor loadings to be identical and then testing how well the fixed measurement models fit the different group samples. They should fit equally well to achieve metric invariance. If they do not, the items each measure something different among different groups, and are not directly comparable (van de Schoot, Lugtig, and Hox 2012). Direct comparison is a necessary condition for statistical tests such as regression to the mean to have useful results.

In the ISSP data, the highest-level concern with measurement is that factors are invariant by country, or by country-time point. There is growing evidence in welfare state research that attitudes are multidimensional (Roosma, Gelissen, and van Oorschot 2013); as with the studies finding a difference between social protection (i.e., "intervention") and social insurance (e.g., pensions and health care) in the ISSP (Blekesaune and Quadagno 2003; Döring 1994). However, dimensions are not likely to be orthogonal to one another because social protection and social insurance are two areas of welfare state intervention, and evidence reveals cross-loading between these factors (Döring 1994:21). A social insurance attitude is something akin to protection for the most deserving members of society, what might be seen by the public as the most common social risks affecting everyone, namely aging and health (van Oorschot 2006), rather than social risks that are specific to economic and labor market activities (Buss 2019). The universality of support for old-age and health care items could confound the ideal role scale, especially because the degree of cross-loading is likely to depend on the existing country's current social insurance model (Arts and Gelissen 2002). Countries with stronger social insurance are likely to have stronger cross-loadings due to institutional conditioning of public preferences (Jepperson 1993; Weber 1921). The open empirical question remains whether a single attitude factor exists that pertains to the government's role in intervention across domains, or if this can only be understood as two attitude factors (or more) because the public do not internally view government intervention as a singular thing, in other words a single attitude object (Eagly and Chaiken 1993; Judd and Krosnick 1989).

Some analogous evidence exists of a single factor underlying social insurance and social protection attitudes. In analyzing a 44 question survey about the role of government in the Netherlands, van Oorschott and Meuleman (2012) find a single factor covering the role of government in providing for the unemployed and those who are more at risk; however, that survey did not contain questions about old-age or health care so it is 
difficult to directly compare. When asked about how well individuals could 'make ends meet', they found that respondents similarly evaluate old-age and health with unemployment and disability (ibid.: 93). Therefore, they provide analogous evidence of a single factor across these welfare policy domains including old-age and health care.

In addition to potential confounding from the insurance/protection attitude split, values and authoritarianism may be a source of attitude bias. For example, formerly Communist states might harbor institutionalized norms where questions about government intervention, in particular on price controls, signal a return to a former system and this may uniquely bias response patterns. Moreover, countries that are Communist (i.e., authoritarian) or underwent major transitions after the Cold War, and are economically poorer than their peers may have publics who are institutionally conditioned to see their governments as untrustworthy or ineffectual. This creates a tension in individuals who see a need and a role for the government to intervene to provide social welfare, but at the same time do not believe the government capable of effective policy delivery. Furthermore, if conditions in a society are in great disrepair, individuals may see things such as roads, clean water or an effective police force as more pressing issues than social welfare. This suggests that the level of development or wealth of an entire society leads individuals to be more or less supportive of government provisions of social welfare (Wilensky 1975) Alternatively, cultural factors such as Confucianism or familial values might lead to a higher support of old age response despite the other questions among East Asian or Mediterranean countries for example (Kwon 1997). All of these factors could lead to differences in response patterns across societies even if a single underlying welfare attitude exists.

\section{TeSTING MEASUREMENT INVARIANCE OF THE IDEAL ROLE ISSP QUESTIONS}

I assume reader familiarity with the data, keep analytical talk brief to benefit the non-statistician and provide extensive technical details and code in an Online Appendix ${ }^{5}$. In this analysis I employ samples from all countries and years in the ISSP RoG, leading to over 130 thousand individuals nested in 111 country-years in 48 countries $^{6}$. If the data collected in the ISSP surveys came from samples of populations that contain a ubiquitous underlying ideal role attitude, then the data-generating process is consistent with an hypothesis of metric invariance. This is the first major step in identifying the latent. The next step is to test for scalar invariance, but this is only justifiable after establishing metric invariance which is the primary focus of this paper given it was not done previously. Assuming no major confounding conditions unique to individual or groups of societies, an exploratory factor analysis should support a model with one factor for all seven items in the ISSP's ideal role battery. I established this shown in the tests in the Online Appendix, thus I moved to confirmatory factor analysis (CFA) to determine if all items have the same loadings with the single latent across samples. Table 1 lists the several CFA configurations I test.

\footnotetext{
${ }^{5}$ https://osf.io/8j3va/

${ }^{6}$ With Germany split into two 'countries' to adjudicate between former socialist and non-former socialist historical and economic features.
} 


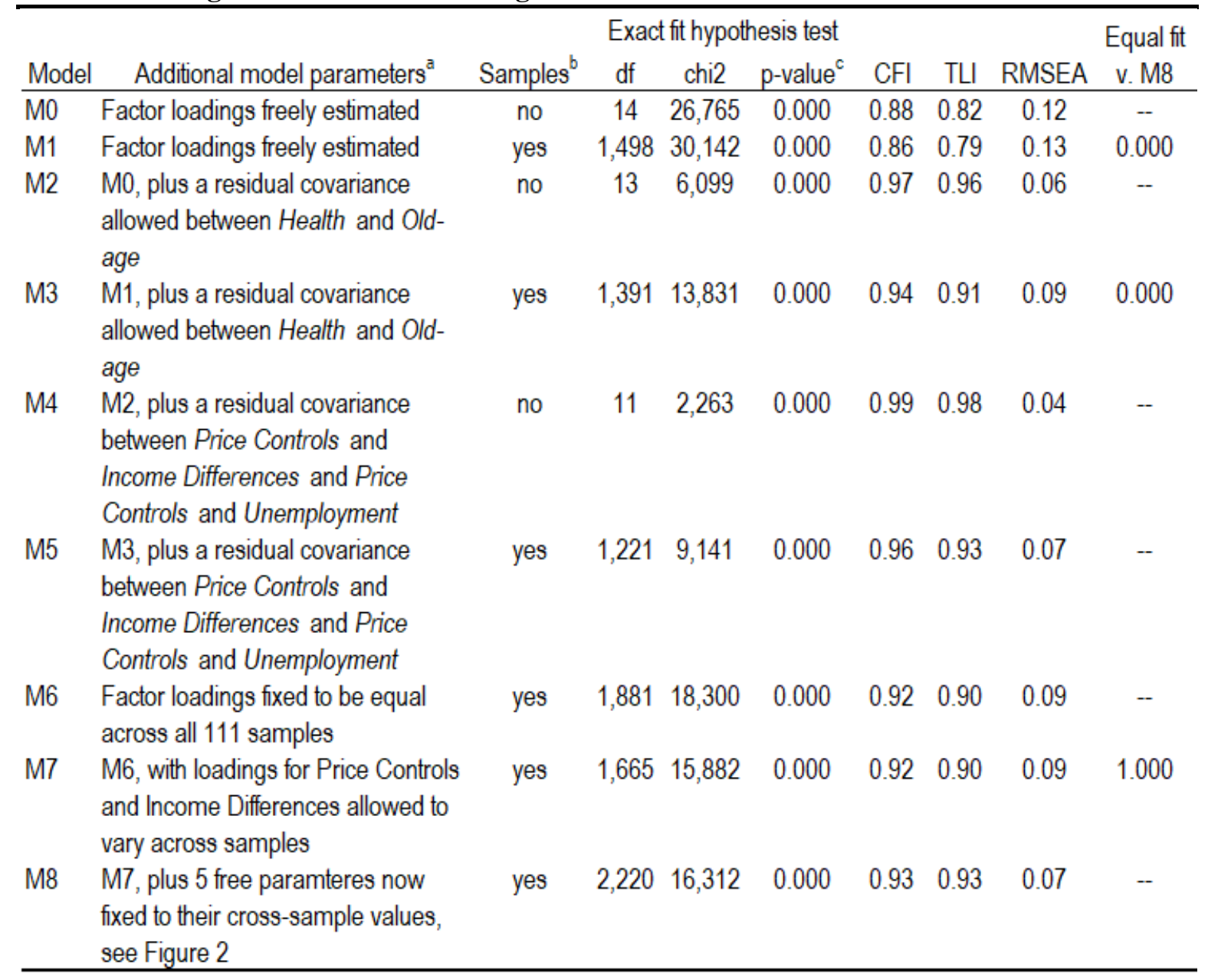

${ }^{a}$ Each model reflects a seven-item factor with the unstandardized factor loading for Jobs fixed to one, estimated using listwise deletion and maximum likelihood.

${ }^{b}$ Indicates whether the model includes sample-specific parameters (multigroup) or not (pooled).

${ }^{c}$ For all models with sample-specific parameters, population-model RMSEA reported, see text.

Using SEM with maximum likelihood and listwise deletion of missing values, M0 reveals strong standardized factor loadings ranging between 0.53 for industry and 0.64 for old-age care, see thick crosses in Figure $1^{7}$. It is possible that unmodeled country heterogeneity confounds these estimates. Therefore, I run M1 with separate CFAs for each country-year sample. The box plots in Figure 1 capture the distribution of standardized loadings for M1 across the 111 samples. The smaller crosses, and the interquartile-range shown in the shaded boxes suggests that over $75 \%$ of the samples ( $\left(1^{\text {st }}\right.$ quartile cutoff in the range) have standardized loadings at 0.50 or above for all items except support for industry at 0.43 . Calculating Cronbach's alpha by country gives an average of 0.75 with $75 \%$ at 0.73 and higher, with the lowest 5 observations averaging 0.62 . Standardized alphas average 0.77 with $75 \%$ at 0.74 and higher, and the lowest 5 show still a strong average of 0.65. By most standards of psychometric measurement these are confirmatory scores across samples, and this is true whether or not all items have identical loadings as assumed in the unstandardized solution (tau-

\footnotetext{
${ }^{7}$ Full results available online, https://osf.io/8j3va/wiki/Supplemental\%20Results/
} 
equivalent), or whether items have identical loadings after standardizing all variances to mean $=0$ and $s d=1$ (Nunnally and Bernstein 1994:232).

Figure 1. Confirmatory Factor Analysis for a Single Factor in the 7-Item "Ideal Role" ISSP Question Battery. Standardized Loadings, Role of Government Module all Countries and Waves 1985-2016.

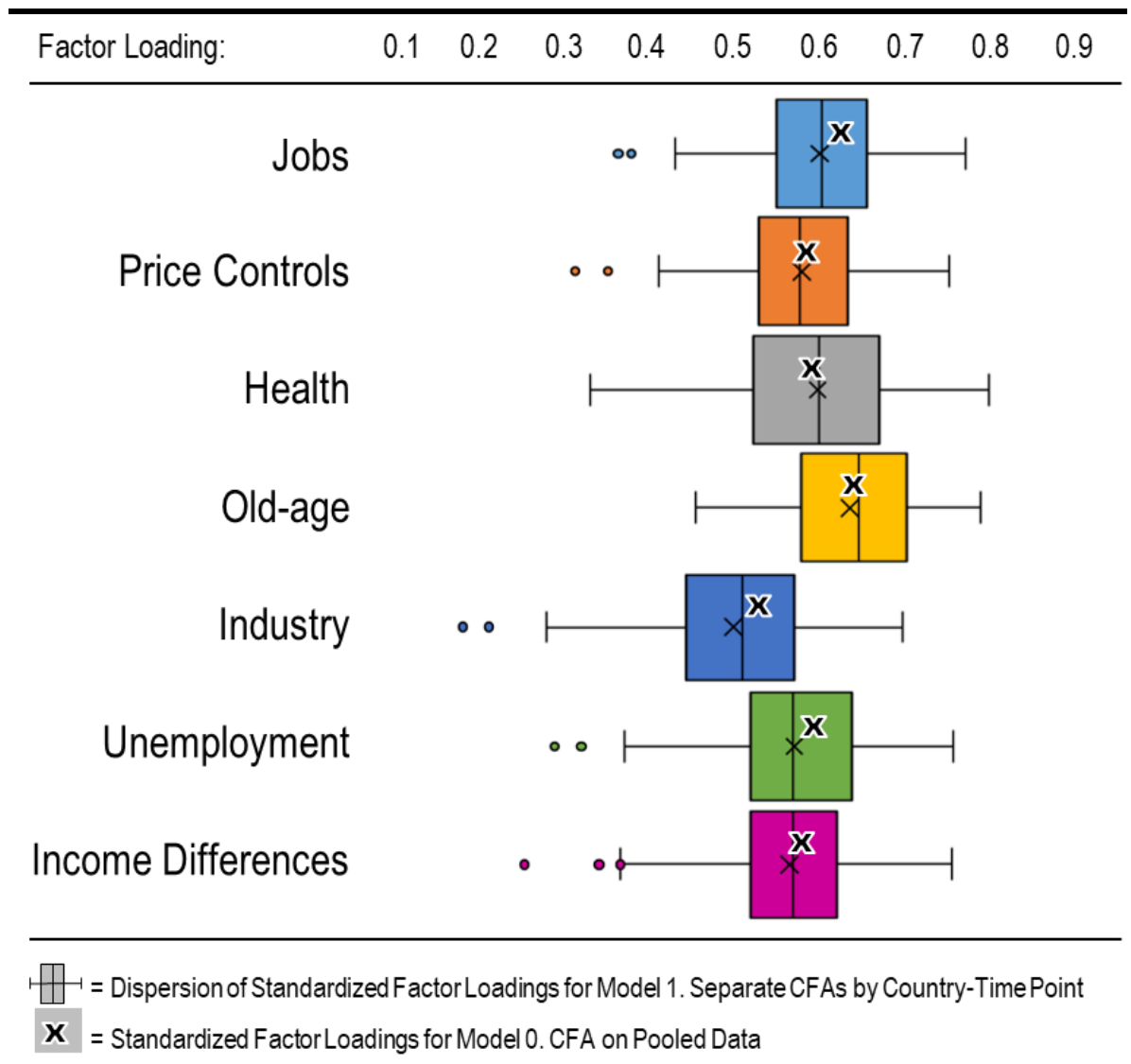

Although cut-off values should be a product of a researcher's goals, 0.70 is routinely cited as a strong standardized alpha and could be taken as evidence of a single factor across $95 \%$ of the 111 samples $^{8}$. However, the common practice of looking at inter-item correlations, factor loadings and alpha does not meet the standards of confirmatory factor analysis developed in the art of SEM (Bollen 1989; Kline 2016 or any SEM text). In fact, the use of alpha is a brand-name phenomenon. Better methods and more stringent tests long surpassed alpha among statisticians as argued by Cronbach himself, but alpha became the path dependent gold-standard of scale assessment still commonly used today (Cronbach and Shavelson 2004). I avoid this pop-science phenomenon and argue that I do not have strong evidence in favor of a single factor yet. Among SEM, the critical test is whether the implied covariances of the researcher's test model are similar to those observed in the saturated model - one that perfectly fits the data allowing everything to freely associate, with zero degrees of model freedom. In other words, the researcher's model should explain what it is trying to explain about the world without making assumptions that force covariances of variables to be significantly different from those observed

\footnotetext{
${ }^{8}$ Standardized loadings derive from potentially different sample distributions so they are not directly comparable, but I compare them here to give a relative sense that these items are strong predictors of a latent attitude variable in each sample.
} 
in the data. The size of the chi-square statistic relative to the degrees of freedom that differentiate the two models provides a p-value for testing this, sometimes known as the exact fit hypothesis test (Kline 2016). For M1, the $\mathrm{p}$-value is less than 0.05 signaling a failed exact fit test and suggesting the model fails to accurately explain the data after allowing a reasonable amount of random measurement error, even though it allows each sample to have its own measurement model.

The exact fit test is the strongest global fit test (Hayduk et al. 2007), so strong in fact that few measurement models pass the test. The failure rate increases with sample size because larger samples are more likely to contain observations of every single minute causal pathway in the data-generating model. Therefore, I might consider a p-value of 0.001 as the cutoff, but M0 and M0 fail the exact fit test at this threshold. This problem is a major reason why indices were developed to relatively asses model fit rather than test exact fit. This began with Jöreskog's goodness-of-fit (GFI) index and two widely used today are Tucker-Lewis (TLI) and comparative-fit (CFI) indices (Bentler 1990). The root mean square error of approximation (RMSEA) is an alternative absolute fit index based on the exact fit test. It is now one of the most widely employed model diagnostics because it accounts for sample size, reflects the underlying chi-square test and allows calculation of confidence intervals (Rigdon 1996).

Setting aside the failed exact fit test, M0 does not perform well on other indices with a TLI of 0.82 and a CLI of 0.88 (values closer to 1.00 and above 0.90 are desirable). The RMSEA of 0.12 misses the typical range of recommended cutoffs such as 0.05 or 0.08 , and even misses the extremely liberal 0.10 (Browne and Cudeck 1992). Model 1 is similarly unconvincing with a TLI of 0.79, CFI of 0.86 and RMSEA of 0.13 . When looking at the results for Model 1 individually by sample, only $20 \%$ achieve an RMSEA below 0.10 . Here it is crucial to distinguish population-model RMSEA from full-model RMSEA. The 0.13 in Model 1 is the RMSEA calculated from the average sample size of the 111 groups and thus represents the entire population of subpopulations. The full-model RMSEA is 0.01 , which indicates great fit, but it is crucial that the model fits each sample well to test invariance, thus all references hereafter refer to population-model RMSEA ${ }^{9}$.

As population RMSEA suggests ill fit, the question arises, why? Theoretical suggestions discussed in the previous section point toward potential multidimensionality, in particular a second factor that causes distinct survey response patterns for the questions on Old-age and Health. Exploratory factor analysis reported in the Online Appendix points toward two factors; however, they have strong cross-loadings. As my interest is in one potential factor linking responses to all seven ideal role questions, I add a residual covariance to the model between the Old-age and Health questions. Results improve, but are not solid evidence of the one underlying factor. The pooled analysis in M2 produces an exact fit $\mathrm{p}$-value $<0.001$, CFI=0.97, TLI=0.96 and RMSEA=0.06 which might be construed as moderate support for a good fitting model, but the real test comes applying the model to each country-time sample separately in M3 resulting in exact fit p-value $<0.001, \mathrm{CFI}=0.94$, TLI $=0.91$ and RMSEA=0.09 which are less convincing; although pointing in the direction of a decent model and supporting $\mathrm{H} 1$ that there is a single factor for the ideal role of government intervention in socio-economic affairs.

\footnotetext{
${ }^{9} \mathrm{RMSEA}=\sqrt{\chi^{2}-d f_{M}}$ divided by $\sqrt{N-1}$; where $\mathrm{N}=1,195.18$ (the sample average) and $\mathrm{df}=14$ (a single sample) for the population-model RMSEA, and $\mathrm{N}=132,665$ and $\mathrm{df}=1554$ (all samples pooled) for the full-model RMSEA.
} 
I have a rough concept that institutional path dependency or cultural factors matter for the noninvariance I observed thus far. However, I have no concrete prior knowledge to use for constructing further model parameters to account for it. Therefore, I look to the modification indices of M2 and find problematic fit of the model to the data from Price Controls and Income Differences questions, and their covariances with some of the other indicators. In particular, indices suggest improvement with an error covariance between Price Controls and Unemployment, and Price Controls and Income Differences, see Online Appendix, "Supplemental Results". This is now a post-hoc model fit, so I revisit cross-national theory to find justification. The questions on price controls and government reducing income differences likely link to formerly socialist political economies, where these questions are suggestive of a socialist system that does not let the market determine prices or the legitimate distribution of occupational pay (Breznau 2010; Evans, Kelley, and Peoples 2010). The question on unemployment is likely linked to economics. Countries with weaker economies should have publics less willing to support the unemployed, potentially leading to response bias (Wilensky 1975). I add these further two error covariances to the next models M4, without sample-specific parameters, p-value $<0.001, \mathrm{CFI}=0.99$, TLI=0.98 and RMSEA=0.04; and M5 with p-value $<0.001$, CFI=0.97, TLI-0.93 and RMSEA=0.07. This now offers support of configural invariance, that there is only one latent factor underlying all seven items. However, I still need to test metric invariance where I constrain the factor loadings to be equal across space and time.

To do this, I must constrain loadings to be equal across all country samples. A long tradition of equivalence testing suggests that models are essentially never fully non-invariant. Full scalar equivalence implies that all loadings, intercepts, variances, and covariances are identical by country. This is a radically conservative expectation when comparing even a handful of countries, much less 111 different country samples. Therefore, I do not expect means and variances to be identical. Means are the main thing that welfare state attitude researchers are interested in comparing because we expect them to differ by type of welfare state or country-specific characteristics (Jæger 2006). Variances too are a product of country heterogeneity. This is the reason I do not test means and nor constrain variances. However, factor loadings should be constrained to test metric invariance, metric equivalence is the fundamental necessary condition to compare items across groups/samples (Steinmetz et al. 2008). This brings me to M6 with measurement coefficients (unstandardized factor loadings) across all 111 country-time samples constrained to equality. This is the appropriate test of $\mathrm{H} 2$, a multigroup confirmatory factor analysis (MGCFA). It achieves something slightly unsatisfactory with $\mathrm{CFI}=0.92, \mathrm{TLI}=0.90$ and $\mathrm{RMSEA}=0.09$.

Yet, expecting all 7 factor loadings to be identical across countries is an unrealistic expectation (Byrne, Shavelson, and Muthén 1989). Thus for M7, I select the loadings for Price Controls and Income Differences to be freely estimated by country. Figure 1 demonstrated that are not particularly stronger or weaker factors than the other items. Their selection is partially theoretically driven because they might have the strongest linkages to norms, institutions or values in a country; at least those for which the world has fought bitterly throughout the Cold War. Moreover, income redistribution as suggested by the Income Difference question links to norms of deservingness and perceptions of freeriding that might be country-specific (Mau 2003; Steensland 2006). Their selection is also partially observationally driven as the modification indices point at these two. With loadings fixed for 5 out of seven items, it provides a direct test of metric invariance. Although not perfect 
according to the most extreme views on measurement invariance because the exact fit test fails (Hayduk 2016), it fits moderately well at CFI=0.92, TLI=0.90 and RMSEA=0.09. See Figure 2, for a diagram.

Although the use of strict cutoffs is not recommended in practice, M7's RMSEA of 0.09 is at the edge of acceptability (Chen et al. 2008). Therefore, two further tests help shed light on metric invariance using M7 as a baseline. The first is the assumption that I know the source of error behind the freely estimated parameters. Following the standard SEM notation and reducing text in Figure 2, these freely estimated parameters are the two loadings for Price Controls $\left[\lambda_{\mathrm{p}}\right]$ and Income Differences $\left[\lambda_{\mathrm{d}}\right]$, and three error covariances for Old-age with Health $\left[\psi_{1}\right]$, Price Controls with Unemployment $\left[\psi_{2}\right]$, and Price Controls with Income Differences [ $\left.\psi_{3}\right]$. If I know that development and institutions are the cause of these disturbances to the scale, I can model these 5 components as constrained (theoretically known) as opposed to freely estimated (unknown) parameters. The second is the idea that in such a massive attempt to assess metric invariance, partial invariance is the most I can hope to identify and such sample diversity and size suggests more generous cutoffs such as RMSEA of 0.09. There are simply too many unknowns in the process and a strong potential for outliers. For example in some settings social desirability or fear of repercussion from an authoritarian government might impact survey responses, or times of great social or political shock and any survey methodology biases (Kuran 1997; Presser and Stinson 1998). Therefore, I could allow a bit more flexibility to test and reduce the level of bias on overall model fit indexes attributable to such outlying.

To substantiate the first point, I run regression analyses of the freely estimated five parameters in M7 as dependent variables with each country-time point sample as the unite of analysis. I aim to test the theoretical arguments to see if they explain the loadings and error covariances. I first develop a trichotomous Communism/socialism variable with countries divided into never socialist or Communist, former Soviet satellite or former British-controlled part of China, and currently socialist or former member of the Soviet Socialist Republic (USSR). These categories are extremely rough, they only provide a heuristic that simultaneously measures the authoritarian nature of Communist-party rule and the values embedded in a socialist organization of society. This gives a rough approximation of the intensity of socialist economic organization and the degree of institutionalization (or institutionalized opposition) of Communism or Communist values. I also regress these error covariances on GDP per capita in 2010 US dollars. Then I predict the error covariances from this regression under the assumption that institutional and economic features of countries are causes of measurement bias in the scale. Figure 2 presents the results of M8, as a measurement model in the form of a path diagram (A), and the regressions explaining the variance of the freely estimated parameters (B). 
Figure 2. Measurement of A Single Factor for the Ideal Role of Government in Socio-Economic Intervention, ISSP 'Role of Government' 1986-2016, 133,655 individuals in 111 country-time samples.



In Figure 2, I present unstandardized factor loadings because these are the only comparable format of loading for testing measurement invariance. I omit the error variance values in the path diagram and omit the full regression results in the explained variance table to keep the focus on the substance of the results ${ }^{10}$. In terms of loadings, the numbers represent the constrained loadings. M7 and M8 have the same loadings constrained, but M8 makes the assumption that development and institutions are the causes of variance in $\lambda_{\mathrm{p}}, \lambda_{\mathrm{d}}, \psi_{1}, \psi_{2}$, and $\psi_{3}$, again on the assumption that I know the cause of their variance. Any known cause and its resulting values are admissible as fixed parameters in an SEM, that is the nature of SEM - to model what I 'know' (assume logically) to be the data generating process. The adjusted-r-squared values support these assumptions. First, the Old-age and Health covariance should not be caused by development, socialist values, or Communist authoritarian annexation. These should simply reflect an attitude toward social insurance one that presumably comes from the social insurance model of each country, thus Communism and GDP as independent variables explain none of the variance. The item loadings and covariances that should link to Communism or authoritarian-rule and the wealth of a society on the other hand explain a great deal of parameter variance, reflected in the adjusted-r-squared values. This is all evidence in support of Model 8's usage of the varying values of $\lambda_{\mathrm{p}}, \lambda_{\mathrm{d}}, \psi_{1}, \psi_{2}$, and $\psi_{3}$ as fixed parameters. Of course the r-squared values suggest a lot of the variance cause remains unexplained, a phenomenon I discuss in the conclusion.

After making the assumptions behind the varying parameters, the statistical tests of M8 demonstrate fit statistics and indices that are reasonable with $\mathrm{CFI}=0.93$, TLI $=0.93$ and RMSEA $=0.07$. Although the model's massive sample size precludes passing the exact fit hypothesis, a second crucial test is the equal fit hypothesis test, which is like the exact fit hypothesis test, but instead of comparing a model to the saturated model it compares a model to another given model (Kline 2016). Therefore, I test whether M3 and M1 fit the data significantly worse than M8. In both cases, I get a p-value $<0.001$ meaning that M1 and M3 are worse, and M8

\footnotetext{
${ }^{10}$ See Online Appendix for full results and additional analyses https://osf.io/8j3va/
} 
is thus preferable, see final column of Table 1. This is the strongest evidence I have in support of M8. It means that the choices I made in constraining parameters and adding error covariances are statistically defensible.

\section{COMPARING COMPARABLE ITEMS}

Having established metric invariance I conclude that the items have the same meaning across these samples. The next step is to fix intercepts and proceed to try and establish scalar invariance. Preliminary analyses find weak support of scalar invariance with an RMSEA at 0.15 and CFI/TLI well below 0.90 . However, if my findings that metric invariance depends on controlling for institutions and development, it is likely that scalar invariance does as well and future research should immediately take up this effort. For now, I present some descriptive evidence of how welfare state attitudes changed over time using the seven items as an indicator. An SEM constructed to measure the ideal role of government in socio-economic intervention attitude offers nearly endless possibilities such as individual-level comparisons across samples, e.g., composition effects; countrylevel comparisons, e.g., comparative public opinion/attitude research; the impact of country-level variables on individual attitudes, e.g., moderation or context effects; and various nested models and cross-classified models. Starting with a latent variables SEM allows researchers to incorporate both endogenous and exogenous variables and account for errors, thus gaining closer approximations of the way data are generated in the observable world - in other words with errors! This paper lays the groundwork. For show I offer a simple comparison of countrytime point latent means predicted from Model 8, collapsed to the country level using the sampling weights provided by the ISSP. I visualize within country changes in the average of the ideal role intervention attitude in rich democracies (Figure 3) and newer democracies of Eastern Europe (Figure 4). I only plot trendlines for countries with at least 3 out of 5 measurement points for rich democracies and 2 out of 3 measurement points for newer democracies. In Figure 3, the long dashed thick black line represents the four countries with 5 measurement points from every wave of the ISSP RoG, and in both figures all countries with the three points of 1996, 2006 and 2016 in the short dashed thick lines. 
Figure 3. Support for Government Socio-Economic Intervention,

Rich Democracies, ISSP RoG 1986-2016

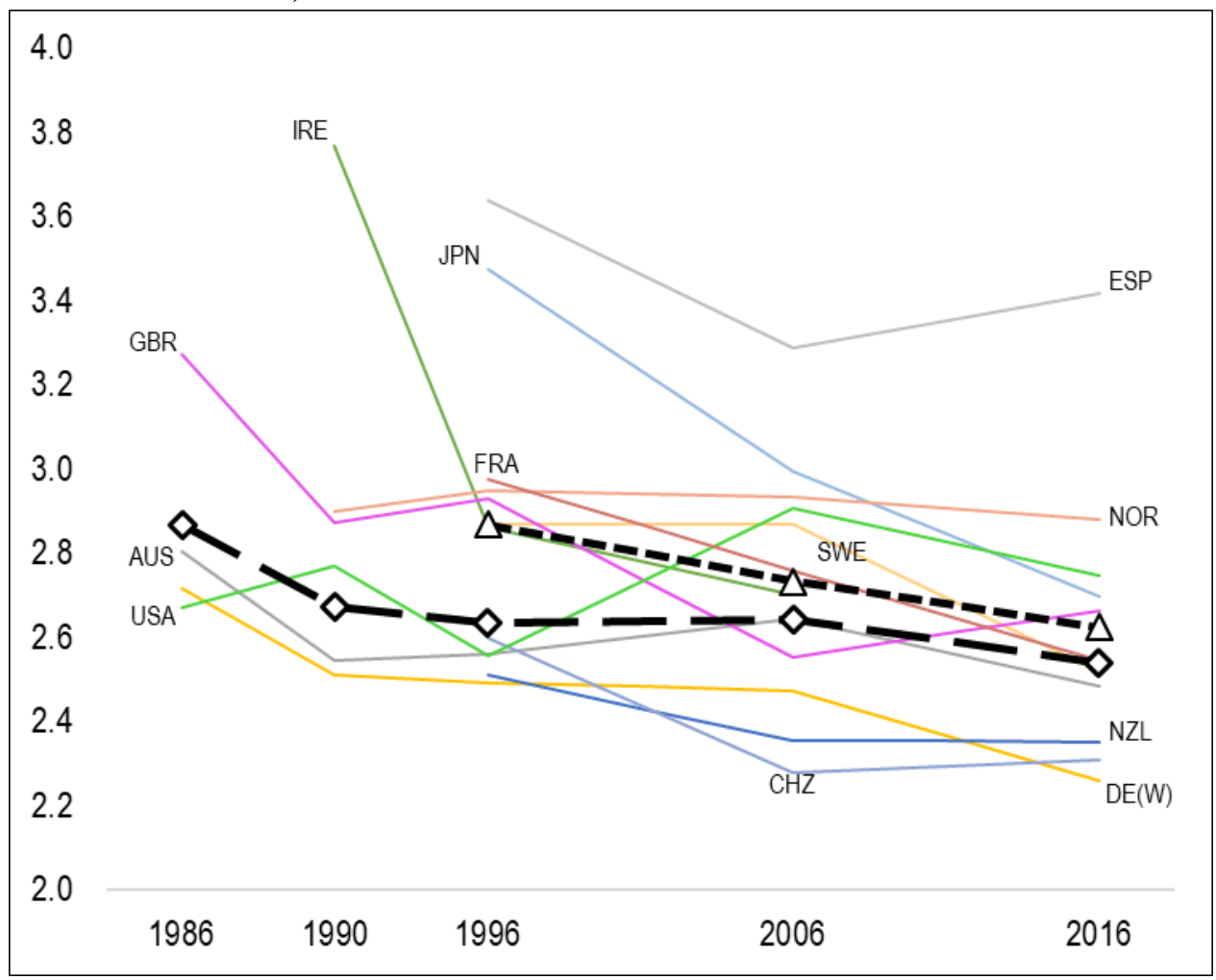

Figure 4. Support for Government Socio-Economic Intervention,

Newer Democracies of Eastern Europe, ISSP RoG 1996-2016

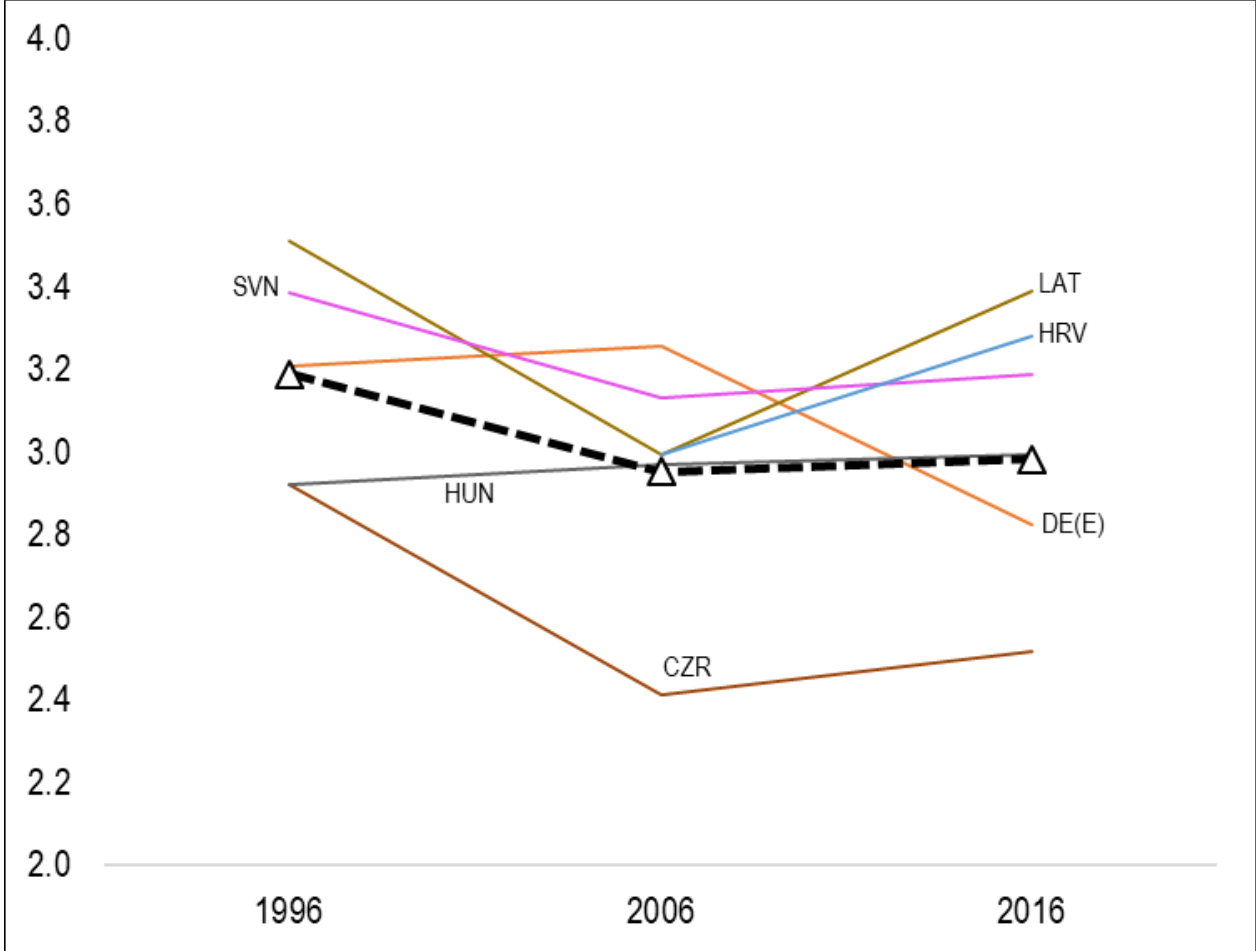

It appears that the seven attitude items measure shifts regarding preferences for government intervention that liberalized on average among the rich democracies in the ISSP RoG both from 1986 through 2016 in Australia, Western Germany, Great Britain and the United States and from 1996 through 2016 for the previous 
four plus France, Japan, Norway, New Zealand, Sweden and Switzerland (Ireland shown but not factored in the average as the series is not complete). There is much debate over this subject in terms of welfare state retrenchment or liberalization of financial markets (Clayton and Pontusson 1998; Stiglitz 2000; Thelen 2012; Zylan and Soule 2000), and whether these impact public attitudes toward social policy (Breznau and Hommerich 2019; Steele 2015; Weakliem, Andersen, and Heath 2005). These figures offer no causal relationship but are clear evidence of significant shifts in the attitudes measured by these seven items across rich democracies (95\% confidence interval, 2016 is significantly lower than the first point in each series). A similar trend appears visually in the newer democracies of Eastern Europe, but the number of countries is far fewer and the differences are not significant at $95 \%$ confidence. Given that there might be variations in sampling or other sample composition effects, it is important to take the mean of indicators presented in Figures 3 and 4 as descriptive only. The main point is that researchers can start to base their comparisons on empirical evidence not yet levied against their longstanding claims, and build better models to account for composition, scalar invariance and other causal pathways of welfare state attitudes (Breznau and Hommerich 2019; Bryan and Jenkins 2016; Schmidt-Catran and Fairbrother 2016).

\section{CONCLUSION}

For decades, scholars theorized a singular underlying attitude about the ideal role of perpetual government socio-economic intervention; however, they often provided little or no statistical substantiation of their theories. In this paper, I provided first evidence of a potential single underlying factor in the ideal role battery of the ISSP RoG module that goes beyond that of anything offered previously. Although not perfect smoking-gun evidence it certainly points in the direction of a latent social welfare policy attitude. I offer the SEM from M8, visualized in Figure 2, as a measurement tool that researchers can immediately apply in their work. I facilitate this implementation by providing all code in the Online Appendix ${ }^{11}$. Although this covers only 43 societies of the world, these are a radically diverse sample of countries from six continents. Moreover, several countries have various measurement points over time, some spanning 30 years. The diversity of the time and space covered in these samples suggests that a successful test of metric equivalence is evidence that these results apply to world society(ies) and are appropriate for investigations of global social policy dynamics. At least around the turn of the Second Millennium.

This exercise contains a marriage of theoretical and methodological lessons. Any theory of a single underlying attitude in the ideal role ISSP RoG battery should contain concessions for other attitudinal factors. The common attitude I investigated in this research regards social welfare, but in a broad sense. The welfare state concept includes everything from pension, health care, labor market, minimum protection and subsidy if not more. Yet, a narrower attitude or bias in attitudes regarding the welfare state relates to social insurance. Everyone faces social risks associated with aging and health. Thus, most everyone should meet deservingness criteria for aging and health, at least general health risks. Also, having the government plan for aging and health

${ }^{11}$ https://osf.io/8j3va/ 
risks does not compromise values of liberal democracy, unlike other forms of intervention into unemployment or income redistribution which may be seen as wasteful, socialistic, encouraging freeriding or benefitting certain social groups (Briggs 1961; Steensland 2006). Following this theoretical logic, my measurement models improved dramatically when allowing for a residual correlation of responses to the items asking about old-age and health care.

The residual old-age and health care correlation could be a second factor, but adding a second factor to the model methodologically could bias the measurement of the first factor, in particular if they are considered unique attitudes that do not correlate. This would be a logical fallacy because government intervention is theoretically a face-value factor of all seven items asking what the government "should" do in socio-economic affairs of the public. Therefore, allowing the residual incorporates the bias of social insurance but sill allows the old-age and health care questions to predict the single underlying attitude. The result is that the factor loadings for old-age and health are smaller than the other 5 items. This means that the relative weight of these two questions is less, and this is a critical lesson for future modeling of this attitude. Giving too much weight to the old-age and health questions will lead to measurement attitudes linked to a given country's social insurance system and thus introduce country heterogeneity into attempts to measure the latent attitude.

Additionally, this exercise is a reminder of the importance of theorizing on institutional effects (Jepperson 1991) in social welfare attitudes. In this case, socialist values and Communist/authoritarian rule may condition attitudes among publics leading to non-invariant response patterns on the questions for prices controls and income redistribution. Theories of institutional effects should bridge culture, values, economics, norms, mores, laws and several other factors that condition how individuals perceive the world, how they expect others to behave, and what normative ideals they espouse (Béland 2007; Breznau 2015; Hall and Taylor 1996; Kalberg 1980; Larsen 2008). This also means attention to the level of development in a society. In this research I focused on measurement in the ISSP questions and used simple categories for institutions as trichotomous with never Communist, former or current annex of Communist-authoritarian rule and currently Communist. In addition to GDP as a single-indicator of development, these are gross oversimplifications of the world and its institutional arrays. I intentionally used these oversimplifications to keep the focus on measurement and provide basic evidence that these things matter, as shown by their strong statistical power to explain measurement variance (as shown in Figure 2).

The study comes with limitations or considerations that should always be in the minds of researchers using ISSP data and incorporating SEM. Normally, comparisons of ISSP data should be done cautiously because of the variation in sampling and survey modes (Jowell 1998). However, measurement modelling is somewhat special in this regard. If there is an underlying factor common to a population, even a non-representative sample should capture it. Nonetheless, only further testing can reveal if and how mode variance might influence measurement Perhaps most importantly, much more research is needed to substantiate a scalar invariant latent. This is no easy task given the demonstrable bias of institutions and context on measurement, if not the giant sample of individuals and country-time points (Kim et al. 2017). In fact, it is likely that requiring strict scalar invariance for comparisons has simply gone to far methodologically speaking, and instead it might be better to aim for partial invariance and consider more flexible approaches such as Bayesian estimation (Davidov, Muthén, and Schmidt 2018). At the same time the standard range of fit testing may be too strict. There are 
voices among SEM methodologists crying out that without rejecting the equal fit test using chi-square and degrees of model freedom (at $\mathrm{p}>0.05$ ), there remains something wrong with a model and thus the theory behind it (Hayduk 2016; Hayduk et al. 2007). Moreover, these same voices point out that even good fitting measurement models can be misspecified (Hayduk 2014). These arguments shift a great deal of burden to the theoretical side of statistical modeling.

Although my theoretical perspective led me to models that statistically explain the biasing error variance and covariances in my measurement models, I am making a strong assumption that all of the variance I observed is caused by development and institutional factors except for random error. The reality is that I can only provide evidence that a portion is predicted by these measures. System change is a complex and drastic event. Scholars simultaneously show that economic performance and ideological commitments, like those generated by institutions of socialism or laissez faire markets, drive attitudes after system transitions; but that these two factors are difficult to disentangle empirically if not theoretically (Anderson and O'Conner 2000; Gugushvili 2015; Rohrschneider and Whitefield 2004). Thus, I cannot claim which is the main culprit between development and institutions, nor can I prove that these are the causal source of all of the observed variance in model parameters. There remains much work to do and much residual variance to explain. Finally, I provide evidence of metric equivalence herein. However, scalar equivalence is the preferred level of invariance for comparison of latent means. I have fixed all intercepts out of the equation. This is similar to fixing them all to be equal but does not test whether the latent mean exhibits a similar degree and direction of bias with respect to the manifest mean across groups. Further work in this area is necessary to support scalar invariance (Steinmetz et al. 2008).

In the end, I conclude that theory, and the range of common statistical tests associated with MGCFA and SEM in general point toward a good fitting model. This includes the equal fit test of chi-square and degrees of freedom when comparing M8 to M3 and M1. M8 thus has everything in its favor except the exact fit test, and scholars are well aware that among samples that run up into the thousands, this test unequivocally fails because there are just too many unobserved causal factors, often many more than there are parameters in a given model (Kline 2016). Given that I have 111 samples with over 133 thousand cases, I accept a failed exact fit hypothesis herein. I argue that this paper provides evidence of an unobserved, but coherent underlying attitude in the RoG ideal role battery that exists across space and time. I offer this as first confirmatory evidence of a global welfare state attitude toward government socio-economic intervention that exhibits partial metric equivalence. This partial equivalence is the same as full metric equivalence if my theoretical assumptions about the sources of bias in the scale are correct. 


\section{REFERENCES}

Anderson, Christopher J. and Kathleen M. O'Conner. 2000. "System Change, Learning and Public Opinion about the Economy." British Journal of Political Science 30(1):147-72.

Ariely, Gal and Eldad Davidov. 2012. "Assessment of Measurement Equivalence with Cross-National and Longitudinal Surveysin Political Science.” European Political Science 11(3):363-77.

Arts, Wil and John Gelissen. 2002. "Three Worlds of Welfare Capitalism or More? A State-of-the-Art Report.” Journal of European Social Policy 12(2):137-58.

Bean, Clive and Elim Papadakis. 1998. "A Comparison of Mass Attitudes towards the Welfare State in Different Institutional Regimes, 1985-1990.” International Journal of Public Opinion Research 10(3):211-36.

Béland, Daniel. 2007. "Ideas and Institutional Change in Social Security: Conversion, Layering, and Policy Drift." Social Science Quarterly 88(1):20-38.

Bentler, Peter M. 1990. “Comparative Fit Indexes in Structural Models.” Psychological Bulletin 107(2):23846.

Blekesaune, Morten and Jill Quadagno. 2003. "Public Attitudes toward Welfare State Policies: A Comparative Analysis of 24 Nations." European Sociological Review 19(5):415-27.

Bollen, Kenneth A. 1989. Structural Equations with Latent Variables. New York, NY: John Wiley \& Sons.

Bowles, S. 1998. "Endogenous Preferences: The Cultural Consequences of Markets and Other Economic Institutions." Journal of Economic Literature 36(1):75-111.

Breznau, Nate. 2010. "Economic Equality and Social Welfare: Policy Preferences in Five Nations." International Journal of Public Opinion Research 22(4):458-84.

Breznau, Nate. 2015. "The Missing Main Effect of Welfare State Regimes: A Replication of 'Social Policy Responsiveness in Developed Democracies’ by Brooks and Manza.” Sociological Science 2:420-41.

Breznau, Nate. 2017. "Positive Returns and Equilibrium: Simultaneous Feedback Between Public Opinion and Social Policy." Policy Studies Journal 45(4):583-612.

Breznau, Nate and Carola Hommerich. 2019. "The Limits of Inequality: Public Support for Social Policy Across Rich Democracies.” International Journal of Social Welfare 28(2):138-51.

Briggs, Asa. 1961. "The Welfare State in Historical Perspective" edited by R. E. Goodin and D. Mitchell. European Journal of Sociology 2(2):221-58.

Brooks, Clem and Jeff Manza. 2006. "Social Policy Responsiveness in Developed Democracies." American Sociological Review 71(3):474-94.

Browne, M. W. and R. Cudeck. 1992. "Alternative Ways of Assessing Model Fit.” Sociological Methods \& Research 21(2):230-58.

Bryan, Mark L. and Stephen P. Jenkins. 2016. "Multilevel Modelling of Country Effects: A Cautionary Tale." European Sociological Review 32(1):3-22.

Buss, Christopher. 2019. "Public Opinion towards Targeted Labour Market Policies: A Vignette Study on the Perceived Deservingness of the Unemployed.” Journal of European Social Policy 29(2):228-240.

Byrne, Barbara M., Richard J. Shavelson, and Bengt Muthén. 1989. "Testing for the Equivalence of Factor 
Covariance and Mean Structures: The Issue of Partial Measurement Invariance." Psychological Bulletin 105(3):456.

Chen, Feinian, Patrick J. Curran, Kenneth A. Bollen, James Kirby, and Pamela Paxton. 2008. "An Empirical Evaluation of the Use of Fixed Cutoff Points in RMSEA Test Statistic in Structural Equation Models.” Sociological Methods \& Research 36(4):462-94.

Clayton, Richard and Jonas Pontusson. 1998. "Welfare-State Retrenchment Revisited: Entitlement Cuts, Public Sector Restructuring, and Inegalitarian Trends in Advanced Capitalist Societies.” World Politics 51(1):67-98.

Cronbach, Lee J. and Richard J. Shavelson. 2004. "My Current Thoughts on Coefficient Alpha and Successor Procedures." Educational and Psychological Measurement 64(3):391-418.

Cudeck, Robert. 2007. "Factor Analysis in the Year 2004: Still Spry at 100." Pp. 1-8 in Factor Analysis at 100: Historical Developments and Future Directions, edited by R. Cudeck and R. C. MacCallum. New Jersey: Lawrence Erlbaum Associates.

Davidov, Eldad, Hermann Dülmer, Elmar Schlüter, Peter Schmidt, and Bart Meuleman. 2012. "Using a Multilevel Structural Equation Modeling Approach to Explain Cross-Cultural Measurement Noninvariance." Journal of Cross-Cultural Psychology 43(4):558-75.

Davidov, Eldad, Bengt Muthén, and Peter Schmidt. 2018. "Measurement Invariance in Cross-National Studies: Challenging Traditional Approaches and Evaluating New Ones." Sociological Methods \& Research 47(4):631-36.

Döring, Herbert. 1994. "Public Perceptions of the Proper Role of the State." West European Politics 17(3):12-31.

Eagly, Alice H. and Shelly Chaiken. 1993. The Psychology of Attitudes. Fort Worth: Harcourt Brace.

Ebbinghaus, Bernhard. 2012. "Comparing Welfare State Regimes: Are Typologies and Ideal or Realistic Strategy?" in ESPAnet Conference. Edinburgh.

Evans, M. D. R., Jonathan Kelley, and Clayton D. Peoples. 2010. "Justifications of Inequality: The Normative Basis of Pay Differentials in 31 Nations." Social Science Quarterly 91(5):1405-31.

Friedrich, Carl J. 1955. “The Political Thought of Neo-Liberalism.” American Political Science Review 49(2):509-25.

Gamble, Andrew. 1994. The Free Economy and the Strong State: The Politics of Thatcherism. London: Macmillan International Higher Education.

Gingrich, Jane. 2014. "Visibility, Values, and Voters: The Informational Role of the Welfare State." The Journal of Politics 76(2):565-80.

Gugushvili, Alexi. 2015. "Self-Interest, Perceptions of Transition and Welfare Preferences in the New Eastern Europe and the South Caucasus." Europe-Asia Studies 67(5):718-46.

Guillaud, Elvire. 2013. "Preferences for Redistribution: An Empirical Analysis over 33 Countries." The Journal of Economic Inequality 11(1):57-78.

Hall, Peter A. and Rosemary C. R. Taylor. 1996. "Political Science and the Three New Institutionalisms." Political Studies 44(5):936-57. 
Hasenfeld, Yeheskel and Jane A. Rafferty. 1989. "The Determinants of Public Attitudes toward the Welfare State." Social Forces 67(4):1027-48.

Hayduk, Leslie A. 2014. "Seeing Perfectly Fitting Factor Models That Are Causally Misspecified:

Understanding That Close-Fitting Models Can Be Worse." Educational and Psychological Measurement 74(6):905-26.

Hayduk, Leslie A. 2016. "Improving Measurement-Invariance Assessments: Correcting Entrenched Testing

Deficiencies.” BMC Medical Research Methodology 16(1):130.

Hayduk, Leslie A., Greta Cummings, Kwame Boadu, Hannah Pazderka-Robinson, and Shelley Boulianne. 2007. "Testing! Testing! One, Two, Three - Testing the Theory in Structural Equation Models!" Personality and Individual Differences 42(5):841-50.

Hayek, F. A. 1996. Individualism and Economic Order. Reprint of. Chicago: University of Chicago Press. Huber, Evelyne and John D. Stephens. 2001. Development and Crisis of the Welfare State: Parties and Policies in Global Markets. Chicago: University of Chicago Press.

Jæger, Mads Meier. 2006. "Welfare Regimes and Attitudes Towards Redistribution: The Regime Hypothesis Revisited.” European Sociological Review 22(2):157-70.

Jepperson, Ronald. 1991. “Institutions, Institutional Effects, and Institutionalism.” Pp. 143-63 in The New Institutionalism in Organizational Analysis, edited by W. W. Powell and P. J. DiMaggio. Chicago: University of Chicago Press.

Jepperson, Ronald L. 1993. "National Scripts: The Varying Construction of Individualism and Opinion Across the Modern Nation-States.” Yale University.

Jowell, Roger. 1998. "How Comparative Is Comparative Research?” American Behavioral Scientist 42(2):168-77.

Judd, Charles M. and Jon A. Krosnick. 1989. "The Structural Bases of Consistency among Political Attitudes: Effects of Political Expertise and Attitude Importance.” Pp. 99-128 in Attitude Structure and Function, edited by A. R. Pratkanis, S. J. Breckler, and A. G. Greenwald. New York and London: Psychology Press Taylor \& Francis Group.

Kalberg, Stephen. 1980. "Max Weber's Types of Rationality: Cornerstones for the Analysis of Rationalization Processes in History." American Journal of Sociology 85(5):1145-79.

Kikuzawa, Saeko, Sigrun Olafsdottir, and Bernice A. Pescosolido. 2008. "Similar Pressures, Different Contexts: Public Attitudes toward Government Intervention for Health Care in 21 Nations.” Journal of Health and Social Behavior 49(4):385-99.

Kim, Eun Sook, Chunhua Cao, Yan Wang, and Diep T. Nguyen. 2017. "Measurement Invariance Testing with Many Groups: A Comparison of Five Approaches.” Structural Equation Modeling: A Multidisciplinary Journal 24(4):524-44.

Kline, Rex B. 2016. Principles and Practice of Structural Equation Modeling. 4th Editio. New York and London: Guilford Press.

Kuran, Timur. 1997. Private Truths, Public Lies: The Social Consequensces of Preference Falsification. Cambridge, MA: Harvard University Press.

Kwon, Huck-Ju. 1997. "Beyond European Welfare Regimes: Comparative Perspectives on East Asian 
Welfare Systems.” Journal of Social Policy 26(4):467-84.

Larsen, Christian Albrekt. 2008. "The Institutional Logic of Welfare Attitudes: How Welfare Regimes

Influence Public Support.” Comparative Political Studies 41(2):145-68.

Mau, Steffen. 2003. The Moral Economy of Welfare States. Britain and Germany Compared. London: Routledge.

Meier Jaeger, Mads. 2009. "United But Divided: Welfare Regimes and the Level and Variance in Public Support for Redistribution." European Sociological Review 25(6):723-37.

Millsap, Roger and William Meredith. 2007. "Factorial Invariance: Historical Perspectives and New

Problems.” Pp. 131-52 in Factor Analysis at 100: Historical Developments and Future Directions,

edited by R. Cudeck and R. C. MacCallum. Mahwah and London: Lawrence Erlbaum Associates.

Munafò, Marcus R., Brian A. Nosek, Dorothy V. M. Bishop, Katherine S. Button, Christopher D. Chambers,

Nathalie Percie du Sert, Uri Simonsohn, Eric-Jan Wagenmakers, Jennifer J. Ware, and John P. A.

Ioannidis. 2017. “A Manifesto for Reproducible Science.” Nature Human Behaviour 1(1):21.

Nunnally, Jum C. and I. H. Bernstein. 1994. Psychometric Theory. Vol. Series in. Third. New York: McGrawHill.

van Oorschot, Wim. 2006. "Making the Difference in Social Europe: Deservingness Perceptions Among

Citizens of European Welfare States.” Journal of European Social Policy 16(1):23-42.

van Oorschot, Wim and Bart Meuleman. 2012. "Welfarism and the Multidimensionality of Welfare State

Legitimacy: Evidence from The Netherlands, 2006.” International Journal of Social Welfare 21(1):7993.

Presser, Stanley and Linda Stinson. 1998. "Data Collection Mode and Social Desirability Bias in Self-

Reported Religious Attendance.” American Sociological Review 63(1):137-45.

Rigdon, Edward E. 1996. "CFI versus RMSEA: A Comparison of Two Fit Indexes for Structural Equation Modeling.” Structural Equation Modeling: A Multidisciplinary Journal 3(4):369-79.

Rohrschneider, Robert and Stephen Whitefield. 2004. "Support for Foreign Ownership and Integration in

Eastern Europe: Economic Interests, Ideological Commitments, and Democratic Context." Comparative Political Studies 37(3):313-39.

Roller, Edeltraud. 1994. "Ideological Basis of the Market Economy: Attitudes toward Distribution Principles and the Role of Government in Western and Eastern Germany." European Sociological Review 10(2):105-17.

Roosma, Femke, John Gelissen, and Wim van Oorschot. 2013. "The Multidimensionality of Welfare State Attitudes: A European Cross-National Study." Social Indicators Research 113(1):235-55.

Schmidt-Catran, Alexander W. and Malcolm Fairbrother. 2016. "The Random Effects in Multilevel Models:

Getting Them Wrong and Getting Them Right.” European Sociological Review 32(1):23-38.

van de Schoot, Rens, Peter Lugtig, and Joop Hox. 2012. "A Checklist for Testing Measurement Invariance."

European Journal of Developmental Psychology 9(4):486-92.

Steele, Liza G. 2015. "Income Inequality, Equal Opportunity, and Attitudes About Redistribution.” Social

Science Quarterly 96(2):444-64. 
Steensland, Brian. 2006. "Cultural Categories and the American Welfare State: The Case of Guaranteed Income Policy." American Journal of Sociology 111(5):1273-1326.

Steinmetz, Holger, Peter Schmidt, Andrea Tina-Booh, Siegrid Wieczorek, and Shalom H. Schwartz. 2008. "Testing Measurement Invariance Using Multigroup CFA: Differences between Educational Groups in Human Values Measurement." Quality \& Quantity 43(4):599-616.

Stiglitz, Joseph E. 2000. “Capital Market Liberalization, Economic Growth, and Instability.” World Development 28(6):1075-86.

Svallfors, Stefan. 2010. "Policy Feedback, Generational Replacement, and Attitudes to State Intervention: Eastern and Western Germany, 1990-2006.” European Political Science Review 2(1):119-35.

Thelen, Kathleen. 2012. "Varieties of Capitalism: Trajectories of Liberalization and the New Politics of Social Solidarity.” Annual Review of Political Science 15(1):137-59.

Thurstone, L. L. 1928. “Attitudes Can Be Measured.” American Journal of Sociology 33(4):529-54.

Weakliem, David L., Robert Andersen, and Anthony F. Heath. 2005. "By Popular Demand: The Effect of Public Opinion on Income Inequality." Comparative Sociology 4:261-84.

Weber, Max. 1921. Economy and Society. Vol. 2. Berkeley: University of California Press (published in 1978).

Wendt, Claus, Monika Mischke, and Michaela Pfeifer. 2011. Welfare States and Public Opinion: Perceptions of Healthcare Systems, Family Policy and Benefits for the Unemployed and Poor in Europe. Cheltenham, UK: Edward Elgar.

Wicherts, Jelte M., Coosje L. S. Veldkamp, Hilde E. M. Augusteijn, Marjan Bakker, Robbie C. M. van Aert, and Marcel A. L. M. van Assen. 2016. "Degrees of Freedom in Planning, Running, Analyzing, and Reporting Psychological Studies: A Checklist to Avoid p-Hacking." Frontiers in Psychology 7:1832.

Wilensky, Harold L. 1975. The Welfare State and Equality: Structural and Ideological Roots of Public Expenditure. Berkeley: University of California Press.

Zylan, Y. and S. A. Soule. 2000. "Ending Welfare as We Know It (Again): Welfare State Retrenchment, 1989-1995." Social Forces 79(2):623-52. 